\title{
In Memoriam: Jerome Seymour Bruner [1915-2016]
}

Jerome Bruner was one of the great psychologists of the 20th century and beyond. He was a founding father of the cognitive revolution; he was perhaps the most important education theorist of the 20th century; and he, along with Jean Piaget, established the study of ontogeny as a major form of psychological explanation.

Bruner did his undergraduate work in psychology at Duke University, receiving his BA in 1937 amidst lively debates among European-trained anti-behaviorists such as Karl Zener and William McDougall. He did his graduate work at Harvard University also in psychology, receiving his $\mathrm{PhD}$ in 1941 amidst equally lively debates on similar topics among such diverse scholars as SS Stevens, BF Skinner, EG Boring, and Gordon Allport. During World War II he served as a social psychologist in the US military.

After the war Bruner returned to Harvard as assistant professor. His experimental research soon established him as a leader in what was called the "new look" in the study of perception. It attacked the widely accepted premise that human psychological functioning began with the raw sense data of perception by showing that even the most basic perceptual judgments were influenced by higherlevel beliefs and values. In 1956 he published the book-heretical at the time-A Study of Thinking, arguably the founding text of cognitive psychology. In 1960 he joined with George Miller to establish the Center for Cognitive Studies, the founding institution of the cognitive revolution. It hosted many of the most influential scholars in the soon-to-emerge cognitive sciences. Bruner's research interests during this time focused on human infants and their perceptual and conceptual worlds. He pioneered several important methods of infant research, and so helped to inspire the mini-revolution in infant studies that followed in the 1970 s and 80 s.

In the 1960s, partly instigated by his appointment as chairman of a governmental committee on education, Bruner was instrumental in revolutionizing American education. The Process of Education (1960) and Toward a Theory of Instruction (1966) were founding texts of American progressive education. He emphasized that children learn best when guided by their own interests while at the same time being scaffolded by more competent adults. He stressed that very young children learn best through action, and only later through symbols and language. The result was his proposal of a "spiral curriculum" in which children were exposed to any and every topic from an early age - always in an age-appropriate manner - and then the topic was revisited at a later age in a manner appropriate for that age. This work was foundational in
Bruner's key role in the creation and design of the US Department of Education's revolutionary Head Start program, as well as his role in elaborating the famous Reggio Emilia (Italy) curriculum for early childhood education.

In 1972 Bruner accepted a professorship at Oxford University. During his eight years there, his major research focus was the study of child language acquisition. Influenced by his friend at Oxford, the ethologist Niko Tinbergen, he proposed to use the then-new technology of video recording to capture language learning in its natural ecological environment of home and family. His empirical research during this time emphasized the way that young children's proclivities as active learners interacted with the language and instruction provided them by adults and others in the culture. In 1975 he published two especially influential theoretical papers - "From communication to language" in the new journal Cognition and "The ontogenesis of speech acts" in the new Journal of Child Language - in which he attempted to refocus the study of language acquisition from Chomsky-inspired syntax to the pragmatics of human communication. His 1983 book Child's Talk: Learning to Use Language summarized his research and theorizing on the topic, and provided a conceptual framework for much subsequent work on child language acquisition.

Bruner returned to the US in 1980 to accept a position at the New School for Social Research, followed by an appointment at the NYU Law School. His interest in the pragmatics of human communication broadened into a focus on narrative thinking and its role in human culture in general. In studying children's early language, he had come to conceptualize a kind of grammar of human action as exemplified by the thematic roles structuring grammatical sentences such as agent, patient, and instrument. This then led naturally to a study of human narratives more generally involving such thematic roles as protagonists, victims, and helpers. The study of culturally significant narratives-the histories, myths, and parables with which a culture identifies-also highlighted the normative dimension of human cognition and culture: humans' understanding of how they ought to think and act. Much of this work was summarized in his two highly influential books (both cited over 10,000 times) Actual Minds, Possible Worlds (1985) and Acts of Meaning (1990). In his later years, Bruner increasingly turned to the application of research in the social sciences - especially research concerned with narrative and normative thinking - to the study of pressing societal problems, especially those commonly addressed in human legal systems. 
Jerome Bruner lived 100 long years, performing important empirical research, fomenting major scientific revolutions, and proposing trenchant psychological theories with applications to basic societal problems. Few other psychologists can lay claim to such a consequential legacy. He will be sorely missed.
Michael Tomasello Max Planck Institute for Evolutionary Anthropology, Germany

Duke University Department of Psychology and Neuroscience, United States 